\title{
Características do Processo Decisório na Cooperação Empresa-Universidade
}

\author{
Geciane Silveira Porto
}

\section{Resumo}

Esta pesquisa teve por objetivo discutir o comportamento do decisor e as características da decisão de desenvolvimento tecnológico por meio da cooperação empresa - universidade. Com este propósito o artigo apresenta o referencial teórico a partir do qual foram definidas 4 hipóteses que foram testadas, por meio de pesquisa empírica, que foi realizada junto a 128 empresas intensivas em tecnologia, utilizando-se testes de diferença de médias e análise fatorial. Foram pesquisadas, tanto as 69 empresas intensivas em tecnologia que decidiram favoravelmente à cooperação quanto as 59 empresas que optaram em não cooperar com a universidade como mecanismo de alcançar o seu desenvolvimento tecnológico. Os resultados são expostos e discutidos em três tópicos: a) decisão de cooperação; b) a estrutura de decisão; e c) as incertezas do processo decisório. A penúltima seção contém as considerações finais.

Palavras-chave: estrutura de decisão; incertezas no processo decisório; cooperação empresauniversidade.

\begin{abstract}
This research analyses the behaviour of the making decision process, and the characteristics of the decision of technological development by means of cooperation industry -university. With this purpose this empirical research was carried out through 128 technological intensive companies, with the purpose to test 4 hypotheses, which had been defined on the basis of the theoretical referential. In order the test own hypotheses mean difference tests and factorial analysis were computed. This research analysed bottle the 69 companies intensive technology that decided to cooperate, and 59 companies that decided not to cooperate with the university in the order to develop technological projects. The results are grouped in three topics: a) the decision of cooperation; b) the structure of decision; and c) the uncertainties of the decision process. Section IX contains our final findings and a bibliographical reference finishes the paper.
\end{abstract}

Key words: structure of decision; uncertainties in the power to decide process; cooperation company-university. 


\section{INTRODUÇÃO}

A decisão de desenvolvimento tecnológico por meio da cooperação com a universidade tem sido foco de poucos estudos e este trabalho contribui para o entendimento da escolha da cooperação como opção para promover o desenvolvimento tecnológico.

A tomada de decisão pode ser definida como o processo de escolha que identifica soluções, avalia os cursos de ação, e implementa plano preferido, para resolução de um problema. Nesta pesquisa a análise foi direcionada para um grupo de decisores (pessoas responsáveis pela decisão de desenvolvimento tecnológico) que atuam em empresas intensivas em tecnologia e por este motivo deparam-se freqüentemente com a necessidade de escolher um caminho que leve suas empresas ao desenvolvimento tecnológico. Assim, dentre as opções existentes, a cooperação é uma das formas de acesso à tecnologia e à inovação. Ao analisar as características referentes à estrutura de decisão, à incerteza, à importância e urgência atribuídas à decisão, buscou-se compreender as características do processo decisório que estão presentes, quando o resultado da decisão é a opção da empresa de realizar a cooperação com a universidade; e quando o resultado da decisão é a opção da empresa de não cooperar e desenvolver a sua tecnologia internamente e/ou com o apoio de outras fontes de tecnologia que não sejam a universidade.

Desta forma o ponto central deste trabalho é justamente buscar a compreensão do comportamento, tanto dos tomadores de decisão que optam por cooperar, quanto daqueles que preferem não utilizar a parceria com a universidade para tal propósito, uma vez que optar ou não pela cooperação é o conteúdo da decisão que eles enfrentam, ao longo das suas trajetórias profissionais, dentro das empresas intensivas em tecnologia que participaram do estudo.

Inicialmente, discute-se a cooperação empresa-universidade e o processo decisório com as suas características. Em seguida, apresenta-se a metodologia utilizada para execução do estudo. Nas seções 6, 7 e 8 os resultados são expostos e discutidos em três tópicos: a) decisão de cooperação; b) a estrutura de decisão; e c) as incertezas do processo decisório. A seção 9 contém as considerações finais e por fim são listadas as referências bibliográficas .

Neste estudo, 22 setores estão representados, com destaque para os setores de 
fabricação de produtos químicos; fabricação de máquinas e equipamentos; fabricação de produtos de metal, afora máquinas e equipamentos; fabricação de artigos de borracha e plástico; e fabricação de máquinas e aparelhos elétricos; fabricação de produtos minerais não-metálicos; fabricação materiais eletrônicos; aparelhos equipamentos de comunicação; fabricação produtos alimentícios e bebidas; metalurgia básica, que totalizam 78 \% da amostra de 128 empresas pesquisadas.

\section{Cooperação Empresa-Universidade}

A cooperação é resultante da ação conjunta de diferentes atores: a empresa, a universidade e o governo, que desenvolvem parcerias, envolvendo simultaneamente todos os atores ou pelo menos 2 representantes deles. De acordo com Plonski (1992), “constitui um modelo de arranjo interinstitucional entre organizações de natureza fundamentalmente distinta, que podem ter finalidades diferentes e adotar formatos bastante diversos. Inclui-se nesse conceito desde interações tênues e pouco comprometedoras, como o oferecimento de estágios profissionalizantes, até vinculações intensas e extensas, como os grandes programas de pesquisa cooperativa, em que chega a ocorrer repartição dos réditos resultantes da comercialização dos seus resultados”. Esse fato indica que a cooperação pode ocorrer de diversas formas, utilizando diferentes mecanismos de interação, Plonski (1999a).

A cooperação não é relação tranqüila, devido às diferenças estruturais e de objetivos que cada organização possui, o que pode gerar percepções e expectativas contraditórias sobre o tema. Nesse sentido, a fim de se estabelecer ambiente minimamente adequado ao trabalho cooperativo, deverão ser definidos os objetivos de cada uma das partes envolvidas, bem como o objetivo que o projeto, como um todo, pretende realizar. A falta de definição de prioridades institucionais e de objetivos claros tem restringido a cooperação às iniciativas pessoais, o que resulta em programas caóticos, cujos resultados instáveis vêm tornando a cooperação um produto da sorte, vinculado ao talento das pessoas que dela participam.

Em relação às atividades de $\mathrm{P} \& \mathrm{D}$, há uma expectativa da comunidade científica de que existam tanto mecanismos de política de natureza geral, destinados a estimular o engajamento das empresas em tais atividades, quanto incentivos à aproximação entre as empresas e as instituições de pesquisa, de forma a promover envolvimento mais intenso destas no atendimento das 
demandas do sistema produtivo (Dagnino, 2003; Guimarães, 1994; Plonski, 1999a; Plonski, 1999b).

O fomento à absorção de tecnologia depende tanto do sistema formal de ensino, quanto de instituições de pesquisa e das empresas. Assim, a vinculação do setor técnico-científico com o empresarial, possibilita o surgimento de capacitação para a absorção de tecnologia.

Nos trabalhos de Bonaccorsi e Piccaluga (1994), Dagnino (2003), Geisler e Rubenstein (1989), Stal (1997), encontra-se uma série de mecanismos de interação, que viabilizam a aquisição de tecnologia por parte das empresas, que são citados a seguir: a) cooperação com universidade; b) relações pessoais informais, quando a universidade não é envolvida; c) relações pessoais e institucionais formais, quando a universidade não é envolvida; d) relações pessoais formais, com convênios entre as universidades e as empresas; e) envolvimento de uma instituição de intermediação; f) convênios formais com objeto definido; g) convênios formais sem objetivo definido; h) criação de estruturas especiais.

Paralelamente à tendência de valorização da cooperação, há uma demanda crescente por especialistas em sua gestão, a qual também deve ser ajustada nessa nova realidade. Isso se torna um problema, porquanto, embora este campo se tenha desenvolvido intensamente nos últimos anos, ainda persiste a carência de pessoas que gerenciem a cooperação; o número de profissionais atuantes na área ainda é reduzido em relação às necessidades existentes. Ainda assim, ressaltase que a gestão é elemento necessário, mas insuficiente para viabilizar o êxito de qualquer projeto de desenvolvimento tecnológico. Desse modo, acreditar que a realização de uma boa gestão resolve as dificuldades é ampliar artificialmente a contribuição da área de gestão.

A diversidade de demandas por parte das empresas, bem como as expectativas e concepções diferenciadas do público universitário necessitam de harmonização em relação às necessidades e ao conhecimento destes atores. Esta constatação não é recente, Fracasso e Santos (1992) já alertavam que, para atingir tal objetivo, "as políticas da universidade têm de ser de tal natureza, que não possam ser impeditivas da existência do modelo que deverá ser de tal modo flexível, que permita formas diferenciadas dentro da mesma universidade, uma vez que nela coexistem diferentes paradigmas de ciência que devem ser preservados”.

A partir da ultima década, a interação de Empresa, Universidade/Instituto de Pesquisa e Governo tem assumido espaço mais expressivo na discussão dos 
pesquisadores; haja vista que "as empresas têm ampliado os recursos externos de $\mathrm{P} \& \mathrm{D}$ em resposta ao aumento da competitividade mundial, e as universidades têm se tornado mais importantes para as indústrias como provedores de P\&D”, e o Governo tem atuado como motivador dessa interação (Etzkowitz e Leydesdorff, 1997). O que nos leva a concluir que esses atores têm mudado as suas formas de agir, colocando abaixo o isolamento entre suas esferas institucionais anteriores.

O que se percebe é que a cultura e a valorização de $P \& D$ são os determinantes para aproximar as empresas dos centros de pesquisa. Assim, quando há o surgimento de uma dificuldade ou restrição, que possa ser solucionada pela universidade, as empresas demonstraram estar predispostas a cooperar; entretanto a limitação de prazo do projeto e a definição de um orçamento são parâmetros mínimos exigidos por parte das empresas (Porto, 1998a).

Dessa forma, guardadas as respectivas características de cada empresa, estas demonstram estar abertas à cooperação, o que não quer dizer que seja tarefa simples. Por parte de ambos os lados, são necessárias adaptações aos respectivos processos de trabalho e a superação de divergências, que podem ser administradas.

\section{O Processo Decisório}

A decisão, em sua essência, representa uma escolha realizada a partir de várias alternativas para se lidar com dado problema que, em geral, envolve a diferença entre a situação que se deseja e a situação real que se encontra. Assim, a tomada de decisão, pode ser representada pelo processo de escolha entre os diversos cursos de ação para resolver um problema. As etapas que constituem este processo podem ser constituídas por este elenco: a) identificação e diagnóstico do problema; b) elaboração de soluções alternativas; c) avaliação das alternativas; d) realização da escolha; e) implementação da decisão; e f) avaliação da decisão. Estas etapas devem ser apoiadas por constante fluxo de informações, criando o feedback necessário para as etapas subseqüentes.

Nutt (1993) salienta que os processos e os procedimentos que constituem a decisão assumem papel determinante, que pode até mesmo levar a desfechos diferenciados. Por trás das etapas do processo decisório, encontra-se o modelo de decisão a ser utilizado. Assim, de acordo com o grau de certeza nos potenciais 
resultados e da crença na existência de uma relação de causa e efeito, o decisor assume diferentes posturas. Este pode vir a assumir desde uma postura intuitiva, em razão das incertezas generalizadas, ou comprometer-se com o resultado, buscando garantir que a decisão tomada seja concretizada. Assim, o processo decisório pode vir a ser prejudicado, devido à escolha de táticas ineficientes em relação ao contexto em que a decisão está acontecendo, afetando também o resultado da decisão final.

\section{Características da Decisão}

A decisão pode ser caracterizada de diversas formas, e muitos são os estudos que buscaram desmistificar o processo decisório e a estrutura de decisão organizacional: Dean e Sharfman (1995); Huber e McDaniel (1986); Machadoda-Silva e Alperstedt (1995); Miller e Friesen (1984); Nutt (1993). No entanto pesquisas sobre a decisão a respeito da realização da cooperação entre universidades e empresas não são tão freqüentes, sendo o foco de poucos estudos, como os de Chen (1997) e National Research Council (1999). Por essa razão, destacam-se a seguir alguns dos elementos que surgem com freqüência, quando se estuda a decisão empresarial e a sua interface com o decisor de um modo geral, elementos que nortearam a realização da pesquisa empírica.

\section{Incerteza}

O decisor, sob condições de incerteza, torna-se mais dependente das informações existentes sobre a situação problema, o que pode levar a um contexto de medo e insegurança psicológica em escolher alternativa que não se encontre dentro da tendência média de suas informações. Dessa forma, o decisor, segundo Grosh e Crain (1995), deverá estar consciente do poder da informação, que é mais bem capturada utilizando simultaneamente tanto instrumentos mais amplos, que indicam a tendência média dos acontecimentos, quanto levantamentos específicos, que descrevem a incerteza da situação específica. Sob condições de incerteza, as informações sobre as alternativas possíveis e os seus resultados são restritos. A incerteza pode resultar de condições externas que estejam em parte ou totalmente fora do controle do executivo, ou simplesmente da falta de acesso a informações fundamentais. Isso torna a incerteza uma restrição para a tomada de decisão, em que o decisor deverá deliberar sobre situações externas imprevisíveis ou sobre as quais não possui as informações necessárias para estabelecer a probabilidade de determinados eventos. 
Porto (2000) destaca a fragilidade do sistema de informações adotado pelas empresas que

"condiciona a qualidade da decisão a aspectos pouco racionais, muito mais ligados à percepção do decisor, sua inserção no meio empresarial, seus pressupostos culturais do que uma análise racional da situação problema a ser definida. Assim, não só a competência do decisor passa a interferir diretamente no resultado da decisão, mas a forma como ele vê e interpreta o problema. A análise poderá levar a desdobramentos muito diferentes de uma situação em que a disponibilidade de informações levaria a uma reflexão mais aprofundada e com maior potencial de êxito e imparcialidade no julgamento, no que se refere à opção de desenvolvimento tecnológico por meio da cooperação empresa-universidade”.

Assim, no que diz respeito à decisão sobre cooperação, espera-se que a disponibilidade de informações, tais como as áreas de competência da universidade, seu histórico de relacionamento com a empresa e a disponibilidade de fundos para desenvolvimento de projetos em parceria possam vir a pesar favoravelmente na decisão de escolha da universidade como parceira tecnológica, tendo em vista a sua contribuição para a diminuição do nível de incertezas geradas no processo decisório.

A escolha de alternativa dentro de um conjunto de opções requer a solução de conflitos para determinar a preferência por uma das alternativas; todo esse processo se torna difícil pelas incertezas inerentes às próprias escolhas, tendo em vista as distorções que ocorrem nas informações que subsidiam o processo decisório (Russo et al., 1996).

É nesse cenário de conflitos que o decisor deverá optar por uma solução para seus problemas tecnológicos. Dessa forma, não apenas a busca da melhor solução técnica deverá ser considerada, mas também a opção que possa contar com o apoio da coalizão dominante, quando esta envolver volumes mais elevados de recursos financeiros, ou interferir na busca ou manutenção da liderança tecnológica, como no caso das empresas intensivas em tecnologia. Assim, a opção de desenvolvimento tecnológico por meio da cooperação com a universidade, em detrimento de outras opções como, a aquisição, o licenciamento, a transferência da matriz, etc., pode não ser vista apenas como decisão técnica, mas como escolha política dentro da organização. 


\section{Estrutura de Decisão}

A identificação e análise do nível hierárquico, em que as decisões podem acontecer, colaboram para o entendimento da amplitude da decisão. Quanto mais alto o nível hierárquico em que as decisões ocorrem, mais ampla pode vir a ser a sua abrangência, enquanto os níveis operacionais se preocupam com decisões bem mais específicas.

De acordo com Huber e McDaniel (1986), o desenho dos procedimentos relacionados às unidades de decisão é resultante das características organizacionais de centralização, especialização e flexibilidade e da sua otimização. Ainda segundo Huber e McDaniel (1986), é relevante para alcançar um bom desempenho organizacional "designar a autoridade do processo decisório para níveis hierárquicos que minimizam a combinação entre custos e falta de informação sobre: a) situação problema; b) a situação global da organização, e c) políticas organizacionais apropriadas”. Enquanto na estrutura centralizada as decisões são tomadas pelo alto escalão ou mesmo por um dos dirigentes, na estrutura descentralizada o poder de decisão está disperso em diferentes níveis organizacionais.

A natureza dos processos decisórios, vinculada ao tipo de decisão, e as informações disponíveis sobre a situação que está exigindo uma decisão determinam a qualidade da decisão. A informação, em termos da sua disponibilidade e qualidade, é que vai permitir ao decisor realizar a escolha mais apropriada, tanto na decisão individual quanto em grupo.

Destaca-se que as tarefas mais suscetíveis à distorção de informações podem ser aquelas menos estruturadas, tanto em relação à natureza da informação como na clareza dos critérios para uma solução bem sucedida. Em tarefas bem estruturadas, em que a distorção das informações é menor, a dificuldade localizase na própria definição das potenciais soluções, (Russo et al., 1996).

As decisões podem ser tanto programadas quanto não programadas; a dificuldade, no entanto, concentra-se quando a empresa não apresenta estrutura de decisão coerente, o que pode tornar até a mais rotineira das decisões uma fonte de problemas. A falta de uma indicação precisa de que a estrutura de decisão, representada pela formalização do processo, suporte do staff e controle sobre a decisão, interfere na concretização da cooperação, levou-nos a questionar se a sua existência contribuiria para a modificação do resultado da decisão sobre cooperação com a universidade para desenvolvimento tecnológico. 


\section{AAutonomia da Decisão em Cenário de Internacionalização de P\&D nas Empresas}

O processo de internacionalização das atividades de P\&D tornou-se uma realidade na qual as estruturas passam a ser geograficamente distribuídas, mas com o controle e a coordenação das atividades de P\&D e de inovação intensificados dentro de um centro próprio e principal (Gerybadze e Reger, 1999).

A decisão de centralização versus descentralização de $\mathrm{P} \& \mathrm{D}$ nas empresas implica a definição do grau de autonomia que a corporação pretende conceder às suas unidades e conseqüentemente da forma e intensidade com que deverá exercer o controle sobre as linhas de pesquisa que estão sendo analisadas e escolhidas pela área.

Chen (1997), ao analisar a centralização versus descentralização, sugere que há "necessidade de manter uma maior abertura sobre a natureza do processo de tomada de decisão em $P \& D$ colaborativo e onde as decisões são tomadas, dentro de multi-locais corporativos”. Assim, a internacionalização de P\&D não constituiria apenas um processo de realocação das funções de P\&D em escala global. Em vez disso, o autor indica que as empresas tentariam extrair as informações técnicas e de mercado mais relevantes, que podem surgir fora do mercado doméstico, e que embasam o processo decisório de maneira mais consistente. Em organizações com centros de P\&D descentralizados, há por parte destes centros maior controle sobre a decisão de desenvolvimento tecnológico em parceria com universidades/ institutos de pesquisa locais; no entanto a decisão para forjar a colaboração em P\&D é privilégio dos quartéis generais das grandes corporações, para obter a coordenação estratégica global.

Dessa forma, em cenário de internacionalização de P\&D cada vez mais freqüente, ao se discutir o processo decisório, faz-se necessário analisar os aspectos relacionados ao controle existente dentro das estruturas dos centros de P\&D, em especial nas empresas transnacionais, porque a existência da centralização poderá levar à perda do controle sobre a decisão a respeito de P\&D na subsidiária, aqui instalada, e conseqüentemente a interferência sobre a autonomia de decisão a respeito de como devem ser desenvolvidas as pesquisas na organização. O que, em última análise, implicaria dificuldades para viabilizar a opção de desenvolvimento de pesquisas em parcerias com universidades nacionais, justamente pela falta de autonomia em decisões desse âmbito. 
Ao analisar a decisão favorável ao desenvolvimento tecnológico por meio da cooperação empresa - universidade, alguns aspectos devem ser considerados: a) Há a necessidade de autonomia para decidir como será realizado o desenvolvimento tecnológico que a empresa almeja, se por meio de desenvolvimento interno, por meio de contratação, via aquisição e/ou licenciamento, transferência da matriz ou, por fim, por meio da parceria com a universidade. b) O locus do controle (Chen, 1997) impactará o processo de negociação, interferindo na decisão final. Deverá ser analisado sob quais condições um gerente de $\mathrm{P} \& \mathrm{D}$ decidirá sobre um contrato de cooperação empresa - universidade, e sob quais condições deverá ser consultada a direção da empresa.

Para Mintzberg (1995), o controle exercido sobre a coleta e análise das informações que deverá embasar a referida tomada de decisão, implica em forma de controle sobre o próprio processo decisório.

Assim, há a expectativa de que as empresas estabeleçam para a área de P\&D determinado grau de autonomia semelhante àquele de que as demais áreas organizacionais dispõem. Dessa maneira, em arranjos organizacionais mais descentralizados, a decisão sobre a cooperação poderá também ser descentralizada em relação à matriz.

\section{Metodologia}

A pesquisa realizada foi um levantamento descritivo (Kerlinger, 1980), cuja amostragem foi não probabilística de voluntários. Foram enviados, pelo correio, questionários para 562 tomadores de decisão de empresas intensivas em tecnologia, e também disponibilizados na internet. A amostra final foi constituída de 128 respostas válidas.

Com o propósito de interpretar um fenômeno complexo, neste caso em particular a decisão a respeito da cooperação empresa-universidade, levantaram-se 4 hipóteses, que foram testadas utilizando-se testes de diferença de médias e análise fatorial (Kelinger, 1980, Hair et alii, 1995, Malhotra, 1996 e Pereira, 1999). A seguir, apresentam-se os resultados encontrados na pesquisa e a discussão associada a cada uma das quatro hipóteses formuladas. 


\section{A Decisão de Desenvolvimento Tecnológico Por Meio da Cooperação Empresa-Universidade}

Entre as empresas que participaram deste estudo, 53,8\% já realizaram ou estão desenvolvendo algum projeto em cooperação com a universidade e 46,3\% optaram por não realizar projetos em cooperação com a universidade. Dentre as universidades com as quais as empresas já realizam ou ainda mantêm parceiras destacam-se a USP, 18\%; Unicamp, 10\%; UFSCar, 7\%; UFRGS, 6\%; UFSC, 5\%; UFMG, 5\%; UFV, 4\%.

Observa-se que 55\% das empresas indicaram a existência de P\&D formal; destas 48\% apresentam área de P\&D no nível de gerência; e em 22\% das empresas encontra-se no nível de diretoria. Esses dados indicam a preocupação por parte dessas empresas em ter uma função estruturada de $P \& D$, assumindo características de P\&D de $3^{a}$ geração, segundo a classificação de Roussel et al. (1992). Mesmo nas empresas que não possuem $P \& D$ formal, há preocupação com atividade mais estruturada de inovação, a qual fica a cargo da diretoria industrial.

A maioria dos respondentes (61\%) encontra-se acima dos 46 anos de idade, trabalham há mais de 16 anos nas empresas (79\%) e estão ocupando o atual cargo entre 2 e 5 anos (38\%). Isso indica certa maturidade e estabilidade dos decisores nas empresas. Há grande concentração nos cargos de primeiro escalão, com destaque para a diretoria industrial com 13\%, presidente e/ou superintendente com $10 \%$; já as gerências funcionais, responsáveis pelas áreas fins da empresa, constituem $26 \%$ da amostra.

Antes de iniciar a análise sobre a estrutura organizacional para apoiar o processo decisório e a existência de incertezas que podem levar a diferentes soluções, torna-se fundamental verificar como o decisor avalia a decisão a respeito da cooperação, em termos de sua importância e urgência.

No que diz respeito à importância e urgência inerentes ao processo decisório, foi formulada a seguinte hipótese nula: $\mathbf{H}_{01}$ : $\mathbf{A}$ avaliação da importância $\mathbf{e}$ urgência da decisão não diferem em função da decisão sobre cooperação com a universidade.

Observa-se que, na avaliação dos decisores, a importância atribuída à decisão a respeito da cooperação é elevada em $37,9 \%$ dos casos, enquanto em termos de urgência é considerada pouca por 35,2\% dos respondentes. 
Na Tabela 1, apresenta-se o resultado do teste de diferença das médias, o qual rejeita $\mathrm{H}_{01}$. Conclui-se que a avaliação da importância e urgência da decisão difere em função da existência da decisão de cooperação com a universidade. Assim, nas empresas que cooperam com a universidade essa decisão tende a ser considerada de elevada importância, e deve ser tratada com certa urgência, diferentemente da visão encontrada em empresas que nunca cooperaram, que atribuem menor importância e urgência a este tipo de decisão.

\section{Tabela 1: Teste t para Importância e Urgência Atribuídas à Decisão de Cooperação}

\begin{tabular}{llllll}
\hline & Média Coopera & Média Não Coopera & $\mathrm{t}$ & Sig. (2-tailed) & $\mathrm{S} / \mathrm{NS}$ \\
\hline Importância da decisão & 4,22 & 3,43 & 3,936 & 0,000 & $\mathrm{~S} * * *$ \\
Urgência da decisão & 3,84 & 3,00 & 3,980 & 0,000 & $\mathrm{~S} * * *$ \\
\hline
\end{tabular}

Escala utilizada: $\mathrm{NH}=$ nenhuma; $\mathrm{MP}=$ muito pouca; $\mathrm{P}=$ pouca; $\mathrm{MP}=$ muito pouca; $\mathrm{E}=$ elevada; $\mathrm{ME}=$ muito elevada; $\mathrm{T}=$ total. Nível de significância: $* * *=1 \% ; * *=5 \%$; *= $10 \% \mathrm{e}$ NS = não significante.

\section{A Estrutura de Decisão}

Já no que se refere à área responsável pela decisão de desenvolvimento tecnológico, por meio da cooperação com a universidade, o status organizacional desta área com expressiva maioria de 56\%, é a direção da empresa, o que indica a importância estratégica dessa decisão, enquanto $29 \%$ das decisões são de responsabilidade da gerência e 13\% da presidência.

Dentre as características da decisão existem aquelas ligadas à existência de uma estrutura que deverá apoiar o processo decisório. Neste estudo, adotaramse os parâmetros da formalização, apoio do staff e centralização/ descentralização do processo, desdobrado na identificação da existência de controle sobre a decisão e na comparação do status que a área organizacional, responsável pela decisão de cooperação, ocupa na estrutura da empresa. A hipótese nula testada foi: $\mathbf{H}_{\mathbf{0 2}}$ : A estrutura de decisão não interfere na decisão sobre cooperação.

No Quadro 1, o teste $\chi^{2}$, em nível de significância de $1 \%$, indica a associação entre a existência de uma área formal de P\&D e a existência de cooperação com a universidade como opção para desenvolvimento tecnológico. 


\section{Quadro 1: Existência de Cooperação $X$ Existência de Área Formal de P\&D}

\begin{tabular}{|c|c|c|c|c|c|}
\hline & & & \multicolumn{2}{|c|}{ Existência de P\&D formal } & \multirow[b]{2}{*}{ Total } \\
\hline & & & $\begin{array}{c}P \& D \\
\text { formal }\end{array}$ & $\begin{array}{l}\text { Não possui } \\
\text { P\&D formal }\end{array}$ & \\
\hline \multirow{4}{*}{$\begin{array}{l}\text { Existência Projeto } \\
\text { em Cooperação }\end{array}$} & Coopera Universidade & $\mathrm{n}$ & 51 & 18 & 69 \\
\hline & & $\%$ & $73,9 \%$ & $26,1 \%$ & $100,0 \%$ \\
\hline & Não coopera & $\mathrm{n}$ & 19 & 40 & 59 \\
\hline & & $\%$ & $32,2 \%$ & $67,8 \%$ & $100,0 \%$ \\
\hline \multirow[t]{2}{*}{ Total } & & $n$ & 70 & 58 & 128 \\
\hline & & $\%$ & $54,7 \%$ & $45,3 \%$ & $100,0 \%$ \\
\hline
\end{tabular}

Pearson chi-square $=22,328 ; \alpha=0,000 * * *$

No conjunto de empresas que cooperam, o status da área de P\&D em 20\% das empresas é de diretoria; em 46\% das empresas é de gerência; e de departamento em $18 \%$ delas. Já a posição que a área de P\&D formal ocupa na estrutura organizacional nas empresas que não cooperam com a universidade é em 26\% dos casos de diretoria; em 53\% como de gerência; e de departamento em 11\% das empresas. Dessa forma, há maior freqüência de P\&D ocupando o $2^{\circ}$.e $3^{\circ}$. escalão em empresas que cooperam, enquanto, em empresas que não cooperam, a área de P\&D é um pouco mais freqüente no $1^{\circ}$. e $2^{\circ}$. escalão.

Não foi encontrada diferença com nível de significância aceitável entre o nível organizacional dos cargos dos decisores e a existência da decisão de cooperação.

A seguir, analisa-se o grau de formalização do processo decisório. No Quadro 2 , o teste $\chi^{2}$, em nível de significância de 5\%, indica a associação entre a existência de cooperação e o grau de formalização do processo decisório. As empresas que apresentam menor formalização em seu processo decisório apresentam também menor incidência de projetos em cooperação com a universidade. Com destaque para a existência de nenhuma formalização, em 22\% das empresas que não cooperam. Já as empresas que cooperam apresentam graus mais elevados de formalização do seu processo decisório.

\section{Quadro 2: Existência de Cooperação X Formalização do Processo Decisório}

\begin{tabular}{|c|c|c|c|c|c|c|c|c|}
\hline & & & \multicolumn{5}{|c|}{ Formalização do Processo Decisório } & \multirow[b]{2}{*}{ Total } \\
\hline & & & Nenhuma & 2 & 3 & 4 & Total & \\
\hline \multirow{4}{*}{$\begin{array}{l}\text { Existência Projeto } \\
\text { em Cooperação }\end{array}$} & Coopera Universidade & $\mathrm{n}$ & 3 & 29 & 18 & 12 & 7 & 69 \\
\hline & & $\%$ & $4,3 \%$ & $42,0 \%$ & $26,1 \%$ & $17,4 \%$ & $10,1 \%$ & $100,0 \%$ \\
\hline & Não coopera & $n$ & 13 & 27 & 9 & 6 & 4 & 59 \\
\hline & & $\%$ & $22,0 \%$ & $45,8 \%$ & $15,3 \%$ & $10,2 \%$ & $6,8 \%$ & $100,0 \%$ \\
\hline \multirow[t]{2}{*}{ Total } & & $n$ & 16 & 56 & 27 & 18 & 11 & 128 \\
\hline & & $\%$ & $12,5 \%$ & $43,8 \%$ & $21,1 \%$ & $14,1 \%$ & $8,6 \%$ & $100,0 \%$ \\
\hline
\end{tabular}

Pearson Chi-square $=11,428 \alpha 0,022 * *$ 
No Quadro 3, o teste $\chi^{2}$, embora em nível de significância de $11 \%$, indica a associação entre a existência de cooperação e a existência de apoio à decisão por parte do staff da empresa.

\section{Quadro 3: Existência de Cooperação com a Universidade X Apoio à Decisão}

\begin{tabular}{|c|c|c|c|c|c|c|c|c|}
\hline & & & \multicolumn{5}{|c|}{ Existência de suporte à Decisão } & \multirow[b]{2}{*}{ Total } \\
\hline & & & nenhum & pouco & parcial & muito & total & \\
\hline \multirow{4}{*}{$\begin{array}{l}\text { Existência Projeto } \\
\text { em Cooperação }\end{array}$} & Coopera Universidade & $\mathrm{n}$ & 2 & 13 & 22 & 22 & 10 & 69 \\
\hline & & $\%$ & $2,9 \%$ & $18,8 \%$ & $31,9 \%$ & $31,9 \%$ & $14,5 \%$ & $100,0 \%$ \\
\hline & Não coopera & $\mathrm{n}$ & 8 & 14 & 19 & 11 & 6 & 58 \\
\hline & & $\%$ & $13,8 \%$ & $24,1 \%$ & $32,8 \%$ & $19,0 \%$ & $10,3 \%$ & $100,0 \%$ \\
\hline \multirow[t]{2}{*}{ Total } & & $\mathrm{n}$ & 10 & 27 & 41 & 33 & 16 & 127 \\
\hline & & $\%$ & $7,9 \%$ & $21,3 \%$ & $32,3 \%$ & $26,0 \%$ & $12,6 \%$ & $100,0 \%$ \\
\hline
\end{tabular}

Pearson Chi-square $=7,628 ; \alpha=0,106 *(\text { Significante a } 11 \%)^{(1)}$

Nas empresas que optaram em cooperar com a universidade há a disponibilização de total suporte em 14,5\% e muito suporte em $31,9 \%$ dos casos, em termos de atividades de apoio e/ou auxílio para a coleta de informações a serem disponibilizadas aos decisores, ao longo do processo decisório, sobre a opção de desenvolvimento tecnológico por meio da cooperação empresa-universidade. Enquanto aquelas que não cooperam, disponibilizaram aos decisores pouco suporte em $24,1 \%$, e nenhum suporte em $19,8 \%$ dos casos.

No Quadro 4, verifica-se que em 63\% das empresas que cooperam há parâmetros que limitam a autonomia; e em 36,2\% dos casos estes parâmetros são inexistentes. Já nas empresas que não cooperam há equilíbrio perfeito: metade segue parâmetros e a outra não.

\section{Quadro 4: Existência de Parâmetro que Limitam a Decisão $X$ Existência de Cooperação}

\begin{tabular}{|c|c|c|c|c|c|}
\hline & & & \multicolumn{2}{|c|}{$\begin{array}{c}\text { Parâmetros que limitam a } \\
\text { autonomia }\end{array}$} & \multirow[b]{2}{*}{ Total } \\
\hline & & & $\begin{array}{c}\text { existem } \\
\text { parâmetros }\end{array}$ & $\begin{array}{l}\text { não existem } \\
\text { parâmetros }\end{array}$ & \\
\hline \multirow{4}{*}{$\begin{array}{l}\text { Existência Projeto } \\
\text { em Cooperação }\end{array}$} & Coopera Universidade & $\mathrm{n}$ & 44 & 25 & 69 \\
\hline & & $\%$ & $63,8 \%$ & $36,2 \%$ & $100,0 \%$ \\
\hline & Não coopera & $n$ & 29 & 29 & 58 \\
\hline & & $\%$ & $50,0 \%$ & $50,0 \%$ & $100,0 \%$ \\
\hline \multirow[t]{2}{*}{ Total } & & $\mathrm{n}$ & 73 & 54 & 127 \\
\hline & & $\%$ & $57,5 \%$ & $42,5 \%$ & $100,0 \%$ \\
\hline
\end{tabular}

Pearson Chi-square $\chi^{2}=2,444 ; \alpha=0,118$ (significante a $11 \%$ ) 
O teste de $\chi^{2}$, em um nível de significância de 11\%, confirma a existência de relacionamento entre a existência de parâmetros que limitam a autonomia do decisor e a existência de cooperação com a universidade. Pode-se dizer que em empresas que cooperam com a universidade existem, com mais freqüência, parâmetros que balizam a tomada de decisão, enquanto em empresas que não cooperam há maior freqüência da não existência desses parâmetros.

Tendo em vista que $73 \%$ das empresas que participam desse estudo, afirmaram a existência de parâmetros que balizam a atuação do decisor, apresenta-se na Tabela 2 o detalhamento sobre quais são estes parâmetros. No entanto, ao utilizar $o$ teste $t$, não se constatou diferença significativa na intensidade com que esses parâmetros ocorrem nas empresas, em nenhum dos critérios analisados, tanto para os respondentes que cooperam, quanto para o que não cooperam com a universidade.

\section{Tabela 2: Teste t para Intensidade com que os Parâmetros Existentes Limitam a Autonomia do Decisor em Optar pela Cooperação com a Universidade}

\begin{tabular}{|c|c|c|c|c|c|}
\hline & $\begin{array}{l}\text { Média } \\
\text { Cooper } \\
\text { a }\end{array}$ & $\begin{array}{l}\text { Média } \\
\text { Não } \\
\text { Coopera }\end{array}$ & $\mathrm{t}$ & $\begin{array}{l}\text { Sig. } \\
(2- \\
\text { tailed })\end{array}$ & $\begin{array}{l}\mathrm{S} / \mathrm{N} \\
\mathrm{S}\end{array}$ \\
\hline $\begin{array}{l}\text { Importância estratégica do projeto para a unidade brasileira } \\
\text { (somente para multinacionais) }\end{array}$ & 4,80 & 4,13 & $\begin{array}{l}1,48 \\
5\end{array}$ & 0,151 & NS \\
\hline $\begin{array}{l}\text { Importância estratégica do projeto para a corporação como um } \\
\text { todo }\end{array}$ & 4,67 & 4,41 & $\begin{array}{l}0,93 \\
4\end{array}$ & 0,354 & NS \\
\hline Valor do projeto que está sendo analisado & 4,61 & 4,50 & $\begin{array}{l}0,40 \\
7\end{array}$ & 0,685 & NS \\
\hline Importância estratégica do projeto para a unidade organizacional & 4,45 & 4,10 & $\begin{array}{l}1,14 \\
1\end{array}$ & 0,258 & NS \\
\hline Importância estratégica do projeto para o grupo de pesquisa & 4,05 & 3,53 & $\begin{array}{l}1,56 \\
2\end{array}$ & 0,123 & NS \\
\hline
\end{tabular}

Escala utilizada: $\mathrm{NH}=$ nenhuma; $\mathrm{MP}=$ muito pouca; $\mathrm{P}=$ pouca; $\mathrm{MP}=$ muito pouca; $\mathrm{E}=$ elevada; $\mathrm{ME}=$ muito elevada; $\mathrm{T}=$ total. Nível de significância: $* * *=1 \% ; * *=5 \%$; $*=10 \% \mathrm{e}$ NS = não significante

Destaca-se que os parâmetros que limitam com maior intensidade a autonomia do decisor, em empresas que cooperam são a importância estratégica do projeto, para unidades brasileiras e para a corporação, como um todo, enquanto para aquelas que não cooperam é o valor do projeto e a importância estratégica do projeto para a corporação, como um todo.

Nas empresas que indicaram a existência de limite financeiro como parâmetro que interfere na autonomia da decisão, estes apresentam grande diversidade, 
sendo que a mediana se encontra em $\mathrm{R} \$ 40.000,00$. Salienta-se que a grande maioria das empresas informou que o limite está condicionado à importância do projeto e principalmente à sua natureza, sendo que as particularidades de cada caso devem ser consideradas no momento da decisão.

Ao se realizar o teste de $\chi^{2}$, para identificar diferenças na postura das empresas que cooperam e não cooperam, este não apresentou diferenças significativas nas distribuições referentes à existência de limites financeiros. Com isso, conclui-se que não existe associação entre a existência de parâmetros que estabeleçam limites financeiros para a tomada de decisão e a existência de cooperação. Em ambos os casos, a autonomia do decisor deverá ser balizada pela importância estratégica do projeto para a organização, seja ela nacional ou multinacional e, em segundo lugar, pelo seu valor.

Os resultados dos testes de qui-quadrado e diferença de médias realizados indicam que pode ser rejeitada a $\mathrm{H}_{02}$. Em síntese, pode-se dizer que as empresas que cooperam com a universidade apresentam processo de tomada de decisão mais formalizado, com parâmetros que limitam a autonomia do decisor e com maior suporte por parte das suas áreas de apoio em subsidiar o decisor na referida decisão, o que nos leva a concluir que a estrutura de decisão, utilizada pela empresa, interfere na decisão sobre a cooperação empresa-universidade para desenvolvimento tecnológico.

\section{Incertezas Inerentes ao Processo Decisório}

O processo decisório freqüentemente ocorre em cenário de incertezas, no qual o decisor pode exercer pouco controle para amenizar os riscos e conflitos desse processo. Esse contexto não é muito diferente, quando se trata da decisão de desenvolvimento tecnológico por meio da cooperação, como se apresenta a seguir, quando se testa a seguinte hipótese nula: $\mathbf{H}_{03}$ : Condições de incerteza não interferem na decisão sobre cooperação com a universidade.

Segundo os decisores, as principais incertezas concentram-se em 5 itens que aparecem com freqüência "muito elevada e total": a) A cooperação com a universidade é resultado de um processo decisório analítico e não intuitivo, em que são ponderados os aspectos positivos e negativos sobre a decisão a ser tomada em $42,1 \%$ dos casos. b) As pessoas comunicam aos seus pares os seus interesses 
e suas preferências a respeito da decisão a ser tomada, em 34,7\% dos casos. c) Em uma decisão de cooperação, são analisadas, exaustivamente, as informações pertinentes ao assunto, antes da tomada de decisão, em 33,6\% dos casos. d) Dificuldade de definição dos custos da pesquisa em 31,1\% dos casos. e) Dificuldade de definição de prazos para a conclusão dos projetos em 30,3\% das vezes.

Ao comparar as médias atribuídas a cada quesito, por meio do teste $t$, foram encontrados resultados significativamente diferentes, em níveis de $1 \%$ e $10 \%$. Assim, pode-se dizer que os decisores que cooperam ressaltam que as suas incertezas incidem mais no seguinte elenco: a) concretização dos projetos com o alcance dos resultados previstos no contrato e/ou convênio; b) a cooperação com a universidade é resultado de um processo decisório analítico e não intuitivo, onde são ponderados os aspectos positivos e negativos sobre a decisão a ser tomada; c) a decisão de cooperação é resultante da análise das informações pertinentes, com descaso de informações consideradas irrelevantes ou secundárias; d) as pessoas comunicam aos seus pares os seus interesses e preferências a respeito da decisão a ser tomada.

Nos demais itens, não foram encontradas diferenças significativas nos resultados dos testes. O que indica que essa decisão é tomada após longo processo de discussão dentro da empresa, em que os envolvidos têm a possibilidade de manifestar suas opiniões; há preocupação em analisar todas as informações disponíveis, enquanto a definição de custos e prazos surge com freqüência similar para os dois grupos de empresas, conforme pode ser observado na Tabela 3.

Os resultados do teste, em nível de significância de 1\% e 10\%, indicam que $\mathrm{H}_{03}$ pode ser rejeitada. Assim, pode-se dizer que as incertezas inerentes ao processo decisório interferem na decisão sobre a cooperação empresa-universidade para desenvolvimento tecnológico.

Um aspecto muito interessante do resultado do teste té que as incertezas que interferem na decisão estão mais associadas à forma como o processo de tomada de decisão ocorre dentro da empresa, principalmente no que se refere ao espaço para debate e questionamentos do conteúdo a respeito do que está sendo decidido. Já os aspectos relacionados a custo e prazo, embora apresentem freqüência próxima da elevada, ocorrem de maneira muito semelhante no dois grupos, ou seja, o impacto das incertezas em se definir o custo e o prazo de conclusão do projeto são menores do que os aspectos referentes ao processo de decisão. O que contraria, de certa forma, o discurso corrente de que a 
dificuldade em se definir custo e prazo prejudica, ou mesmo limita a existência de cooperação entre a empresa e a universidade, haja vista que as empresas participantes não apontaram essas incertezas entre as mais freqüentes. Assim, com maior ou menor dificuldade, as empresas têm conseguido superar as dificuldades de estabelecimento dos custos da pesquisa e do tempo necessário para o término do projeto.

\section{Tabela 3: Teste t para a Freqüência das Incertezas Inerentes ao Processo Decisório a Respeito da Cooperação com a Universidade para Desenvolvimento Tecnológico}

\begin{tabular}{|c|c|c|c|c|c|}
\hline & $\begin{array}{l}\text { Média } \\
\text { Coopera }\end{array}$ & $\begin{array}{l}\text { Média nãc } \\
\text { Coopera }\end{array}$ & & $\begin{array}{l}\text { Sig. } \\
(2- \\
\text { tailed })\end{array}$ & $\begin{array}{l}\mathrm{S} / \mathrm{N} \\
\mathrm{S}\end{array}$ \\
\hline $\begin{array}{l}\text { A cooperação com a universidade é resultado de um processo } 4 \\
\text { decisório analítico e não intuitivo, em que são ponderados os } \\
\text { aspectos positivos e negativos da decisão a ser tomada. }\end{array}$ & & 3,6 & $\begin{array}{l}2,93 \\
8\end{array}$ & 0,004 & $\begin{array}{l}\mathrm{S}^{* *} \\
*\end{array}$ \\
\hline $\begin{array}{l}\text { A decisão de cooperação é resultante da análise das informações } 4 \\
\text { pertinentes, com descaso de informações consideradas } \\
\text { irrelevantes ou secundárias. }\end{array}$ & & 3,2 & $\begin{array}{l}3,67 \\
8\end{array}$ & 0,000 & $\begin{array}{l}\mathrm{S}^{* *} \\
*\end{array}$ \\
\hline $\begin{array}{l}\text { As pessoas comunicam aos seus pares os seus interesses e } 4 \\
\text { preferências a respeito da decisão a ser tomada. }\end{array}$ & & 3,6 & $\begin{array}{l}1,68 \\
9\end{array}$ & 0,095 & $\mathrm{~S}^{*}$ \\
\hline $\begin{array}{l}\text { Em uma decisão de cooperação são analisadas exaustivamente } 4 \\
\text { as informações pertinentes ao assunto, antes da tomada de } \\
\text { decisão. }\end{array}$ & & 3,6 & $\begin{array}{l}1,45 \\
7\end{array}$ & 0,149 & NS \\
\hline $\begin{array}{l}\text { Concretização dos projetos com o alcance dos resultados } 3 \\
\text { previstos no contrato e/ou convênio. }\end{array}$ & & 3,3 & $\begin{array}{l}1,67 \\
0\end{array}$ & 0,099 & $\mathrm{~S}^{*}$ \\
\hline $\begin{array}{l}\text { Dificuldade de definição de prazos para a conclusão dos } 3 \\
\text { projetos. }\end{array}$ & & 3,6 & $\begin{array}{l}0,93 \\
1\end{array}$ & 0,354 & NS \\
\hline $\begin{array}{l}\text { A decisão de cooperação é resultado de negociação entre os } 3 \\
\text { membrosdo grupo. }\end{array}$ & & 3,3 & $\begin{array}{l}1,51 \\
8\end{array}$ & 0,132 & NS \\
\hline Dificuldade de definição dos custos da pesquisa. & 3,5 & 3,8 & $\begin{array}{l}0,92 \\
8\end{array}$ & 0,356 & NS \\
\hline $\begin{array}{l}\text { Existência de condições externas que estejam fora do controle } 3 \\
\text { do decisor, que podem interferir no sucesso do projeto de } \\
\text { cooperação com a universidade. }\end{array}$ & & 3,5 & $\begin{array}{l}0,21 \\
5\end{array}$ & 0,830 & NS \\
\hline $\begin{array}{l}\text { Diversidade de alternativas a serem analisadas antes de optar } 3 \\
\text { pela decisão sobre cooperação com a universidade. }\end{array}$ & & 3,6 & $\begin{array}{l}1,21 \\
9\end{array}$ & 0,226 & NS \\
\hline $\begin{array}{l}\text { A decisão de cooperação é resultado do uso do poder e } 3 \\
\text { influência entre membros do grupo. }\end{array}$ & 3,1 & 2,8 & $\begin{array}{l}0,95 \\
3\end{array}$ & 0,343 & NS \\
\hline
\end{tabular}

Escala utilizada: $\mathrm{NH}=$ nenhuma; $\mathrm{MP}=$ muito pouca; $\mathrm{P}=$ pouca; $\mathrm{MP}=$ muito pouca; $\mathrm{E}=$ elevada; $\mathrm{ME}=$ muito elevada; $\mathrm{T}=$ total. Nível de significância: $* * *=1 \%$; ** = 5\%; *=10\% e NS = não significante.

\section{Fatores Referentes às Incertezas do Processo Decisório}

A existência de incertezas é inerente a qualquer processo decisório, situação essa que é intensificada quando o escopo da decisão se reporta ao desenvolvimento 
tecnológico. Assim, buscar-se-á caracterizar, entre a diversidade de incertezas, aquelas que são mais expressivas, quando a decisão envolve a opção de cooperação com a universidade. Com esse propósito foi testada a seguinte hipótese nula. $H_{04}$ : Não existem fatores de incerteza que interfiram na decisão sobre cooperação empresa-universidade.

Como resultado da análise fatorial, dos itens que descrevem as incertezas ao processo decisório, analisadas na seção anterior, foram extraídos três fatores que explicam 70,6\% da variância das variáveis analisadas, descritos na Tabela 4 a seguir: a) Decisão racional, com priorização na coleta e análise das informações com canais de comunicação abertos entre os membros do grupo. b) Decisão racional, com dificuldade de previsão de prazos e custos, além de aspectos externos à organização, contribuindo na formação de incertezas. c) Decisão política, com uso de poder e negociação entre os membros do grupo responsável pela decisão de cooperação.

\section{Tabela 4: Fatores Referentes às Incertezas Inerentes ao Processo Decisório}

\begin{tabular}{|c|c|c|}
\hline $\begin{array}{l}\text { FATORES (Kaiser-Meyer-Olkin Measure of Sampling Adequacy: KMO }=0,841 \text {. } \\
\text { Bartlett's Test of Sphericity : Chi-square }=663,335 ; \text { Sig } 0,000^{* *} \text { ) }\end{array}$ & $\begin{array}{l}\text { Carga } \\
\text { Fatori } \\
\text { al }\end{array}$ & $\begin{array}{l}\text { Total da } \\
\text { variância } \\
\text { Explicada }\end{array}$ \\
\hline $\begin{array}{l}\text { FATOR 1: Priorização na coleta e análise das informações com canais de } \\
\text { comunicação aberto entre os membros do grupo (Decisão Racional) }\end{array}$ & & 32,3 \\
\hline $\begin{array}{l}\text { A decisão de cooperação é resultante da análise das informações pertinentes, com } \\
\text { descaso de informações consideradas irrelevantes ou secundárias. }\end{array}$ & 0,852 & \\
\hline $\begin{array}{l}\text { A cooperação com a universidade é resultado de processo decisório analítico e não } \\
\text { intuitivo, em que são ponderados os aspectos positivos e negativos da decisão a ser } \\
\text { tomada. }\end{array}$ & 0,847 & \\
\hline $\begin{array}{l}\text { Em uma decisão de cooperação, são analisadas, exaustivamente, as informações } \\
\text { pertinentes ao assunto, antes da tomada de decisão. }\end{array}$ & 0,813 & \\
\hline $\begin{array}{l}\text { As pessoas comunicam aos seus pares os seus interesses e preferências a respeito da } \\
\text { decisão a ser tomada. }\end{array}$ & 0,741 & \\
\hline $\begin{array}{l}\text { Concretização dos projetos com o alcance dos resultados previstos no contrato e/ou } \\
\text { convênio. }\end{array}$ & 0,6 & \\
\hline $\begin{array}{l}\text { Fator 2: Dificuldade de previsão de prazos e custos. Aspectos externos à } \\
\text { organização contribuindo na formação de incertezas (Decisão Racional) }\end{array}$ & & $\mathbf{5 7 , 3}$ \\
\hline Dificuldade de definição de prazos para a conclusão dos projetos. & 0,830 & \\
\hline Dificuldade de definição dos custos da pesquisa. & 0,806 & \\
\hline $\begin{array}{l}\text { Existência de condições externas que estejam fora do controle do decisor, que podem } \\
\text { interferir no sucesso do projeto de cooperação com a universidade. }\end{array}$ & 0,785 & \\
\hline $\begin{array}{l}\text { Diversidade de alternativas a serem analisadas antes de optar pela decisão sobre } \\
\text { cooperacão com a universidade. }\end{array}$ & 0,637 & \\
\hline $\begin{array}{l}\text { Fator 3: Uso de Poder \& Negociação entre os membros do grupo responsável pela } \\
\text { decisão de cooperação (Decisão Política) }\end{array}$ & & 70,6 \\
\hline $\begin{array}{l}\text { A decisão de cooperação é resultado do uso do poder e influência entre membros do } \\
\text { grupo. }\end{array}$ & 0,83 & \\
\hline A decisão de cooperação é resultado de uma negociação entre os me & 0,651 & \\
\hline
\end{tabular}

Na Tabela 5, apresenta-se o teste t. Os resultados do teste indicam que se 
rejeita $\mathrm{H}_{04}$; portanto as condições de incerteza interferem na decisão sobre cooperação com a universidade.

Desta forma, pode-se concluir que a decisão de cooperação é racional, e que as incertezas consideradas mais relevantes no processo decisório são aquelas associadas à busca de um mecanismo de coleta e análise das informações. Assim, em organizações que cooperam, é permitido a todos os envolvidos o acesso às informações, com espaço para críticas e opiniões, o que contribui para que a decisão final ocorra de forma bem fundamentada, visando ao alcance dos objetivos listados por ocasião da elaboração do contrato e/ou convênio com a universidade. Por outro lado, as empresas que não cooperam apresentam uma postura de descrédito em relação à possibilidade da ocorrência da decisão racional com base em informações estruturadas.

\section{Tabela 5: Teste t para os Fatores de Incerteza Inerentes ao Processo Decisório}

\begin{tabular}{llllll}
\hline & Média Coopera & Média Não Coopera & $\mathrm{t}$ & Sig.(2-tailed) & $\mathrm{S} / \mathrm{NS}$ \\
\hline Fator_1_incertezas & 0,311 & $\mathbf{- 0 , 3 9 1}$ & 3,852 & 0,000 & $* * *$ \\
Fator_2_incertezas & $-0,120$ & 0,150 & $-1,380$ & 0,171 & $\mathrm{NS}$ \\
Fator_3_incertezas & 0,019 & $-0,023$ & 0,216 & 0,830 & $\mathrm{NS}$ \\
\hline
\end{tabular}

Nível de significância: $* * *=1 \%$; ** = 5\%; *=10\% e NS = não significante

\section{Considerações Finais}

As empresas cujas decisões foram favoráveis à cooperação possuem área de $\mathrm{P} \& \mathrm{D}$ formalizada em sua estrutura organizacional, que aparece com maior freqüência como Gerência de P\&D.

Com referência à estrutura de decisão, pode-se dizer que as empresas que cooperam com a universidade apresentam processo de tomada de decisão mais formalizado, com parâmetros que limitam a autonomia do decisor; no entanto não foi possível associar parâmetros específicos para cada decisão e com maior suporte por parte das suas áreas de apoio em subsidiar o decisor na referida decisão, indicando que a estrutura de decisão utilizada pela empresa interfere na decisão sobre a cooperação empresa-universidade para desenvolvimento tecnológico.

Já a natureza das incertezas está mais relacionada à maneira como o processo de tomada de decisão ocorre dentro da empresa, caracterizando-se como decisão 
racional. As incertezas consideradas mais relevantes para o processo decisório são aquelas associadas à busca de um mecanismo de coleta e análise das informações, canais de comunicação abertos de maneira a permitir a todos os envolvidos o acesso a elas, com espaço para manifestações de críticas e opiniões, o que contribui para que a decisão final ocorra de forma bem fundamentada, o que deverá contribuir para o alcance dos objetivos listados no contrato e/ou convênio com a universidade. Por outro lado, as empresas que não cooperam apresentam uma postura de descrédito em relação à possibilidade da ocorrência da decisão racional com base em informações estruturadas.

Destaca-se que custo e prazo não distinguem a decisão de cooperação, o que contraria, de certa forma, o discurso corrente de que a dificuldade em defini-los prejudica ou mesmo limita a existência de cooperação entre a empresa e a universidade. Assim, com maior ou menor dificuldade as empresas têm conseguido superar as dificuldades, de estabelecimento dos custos da pesquisa e do tempo necessário para o término do projeto.

\section{Nota}

${ }^{1}$ Devido às dificuldades e restrições existentes na realização de estudos quantitativos em ciências sociais, optou-se por admitir o nível de significância de $11 \%$ para o teste, mas com as devidas ressalvas inerentes a esta flexibilização.

\section{Artigo recebido em 18.03.2003. Aprovado em 07.05.2004.}

\section{REFERÊNCIAS BibLIOGRÁficas}

BONACCORSI, A.;

PICCALUGA, A.

A theoretical framework for the evaluation of university-industry relationships. R\&D Management, Oxford, v. 24, n.3, p.229-247, jul. 1994.

CHEN, S-H.

Decision-making in research and development collaboration. Research
Policy, Amsterdam, v. 26, n.1, p.121135, mar. 1997.

\section{DAGNINO, R.}

A Relação Universidade-Empresa no Brasil e o "Argumento da Hélice Tripla”. Revista Brasileira de Inovação-RBI, Rio de Janeiro, v.2, n. 2, p.267-307, dez. 2003. 
DEAN, J. W. Jr.;

SHARFMAN, M. P.

The relationship between procedural rationality and political behavior strategic decisin making. Decision Sciences, Atlanta, v. 24, n. 6, p.10691083, dec. 1995.

ETZKOWITZ, H.;

\section{LEYDESDORFF.}

Introduction to special issue on science policy dimensions of the Triple Helix of university-industrygovernment relations. Science and Public Policy. [S.L.], v.24, n.1, p.2-5, feb. 1997.

\section{FRACASSO, E. M.;}

SANTOS.

Modelos de transferência de tecnologia da universidade para a empresa. Perspectiva Econômica. [S.L.], v. 27, n. 78, p. 57-66, 1992.

\section{GEISLER, E.;}

RUBENSTEIN,A. H.

University-Industry relationships: A review of major issues In: LINK, A. N.; TASSEY, G. (Editors). Cooperative Research Development: The industry-University-Government Relationship Kluwer Academic Press, Boston: 1989, p. 43-64.

\section{GERYBADZE, A.;}

\section{REGER, G}

Globalization of R\&D: recent changes in the management of innovation in transnational corporations. Research Policy. Amsterdam, v. 28, n. 2-3, p. 251274, mar. 1999.
GROSH, D.;

CRAIN, T.

Structure of uncertainty and decision making: an experimental investigation. Decision Science, Atlanta, v.24 n. 4, p. 789-807, july/aug. 1993.

\section{GUIMARÃES, E.A.}

Síntese Setorial: a pesquisa científica e tecnológica e as necessidades do setor produtivo. Brasília: PADCTII. 9, 1994. Mimeografado.

HAIR, J.F.; et al.

Multivariate Data Analysis. New Jersey: Prentice Hall, 1995.

HUBER, G. P.;

MCDANIEL, R.

The decision making paradigm of organizational design. Management Science, Linthicum, v.5, n.32, p. 572589, may 1986.

\section{KERLINGER, F. N.}

Metodologia da pesquisa em Ciências

Sociais: um tratamento conceitual. São Paulo: EPU, 1980.

MACHADO-DA-SILVA, C.;

ALPERSTEDT, G D.

Informática e estrutura de decisão organizacional: um estudo de caso. In: ENCONTRO ANUAL DA ANPAD, 19., 1995, João Pessoa. Anais... João Pessoa: ANPAD, 1995.

MALHOTRA, N. K.

Pesquisa de Marketing. Uma Orientação Aplicada. 3. ed. Porto Alegre: Bookman, 2001. 
MILLER, D. FRIESEN, P, H, A

Longitudinal study of the corporate life cycle. Management Science, Linthicum, v.30, n. 10, p.1161-1183, oct. 1984.

MINTZBERG $\mathrm{H}$.

Criando Organizações Eficazes. São

Paulo: Atlas, 1995.

NATIONAL RESEARCH COUNCIL.

Decision making in the U.S. Department of energy's environmental management office of science and technology. Washington: National Academy Press, 1999.

NUTT, P. C.

The identification of solution ideas during organizational decision making. Management Science, Linthicum, v.39, n.9, p.1071-1085, sep. 1993.

PEREIRA, J. C. R.

Análise de Dados Qualitativos: Estratégias Metodológicas para Ciências da Saúde, Humanas e Sociais. São Paulo: Editora da Universidade de São Paulo, 1999.

PLONSKI, G. A.

A Cooperação Empresa - Universidade no Brasil: um balanço prospectivo. In INTERAÇÃO UNIVERSIDADE EMPRESA. 1999, Brasília. Instituto Brasileiro de Informação em Ciência e Tecnologia, Athalaia, 1999a. p. 76-98.
Visão Estratégica da Cooperação Universidade-Empresa. v. 34, n. 4, São Paulo: RAUSP, 1999b.

(Ed.) Prefacio a la Cooperación Empresa_universid en Iberoamérica, In Cooperación empresa-Universidad en Iberoamérica. São Paulo: CYTED, 1992.

PORTO, G. S.

A decisão empresarial de cooperação empresa universidade para desenvolvimento tecnológico. 2000. 253 f. Tese (Doutorado em Administração) - FEA/USP, São Paulo.

Decision making in business/research institute co-operation for technological development. In: IAMOT, 7., 1998, Orlando, EUA. Proceedings... Orlando, EUA: Elsevier Science, 1998 p. 71.

An experience of International Cooperation in Iberoamerica: the case of CYTED. In: IAMOT, 7., 1998, Orlando, EUA, Procedings... Orlando, EUA: Elsevier Science, 1998b. p. 106.

ROUSSEL, P.A;

SAAD, K.N.;

BOHLIN, N.

Pesquisa \& desenvolvimento: Como integrar P\&D ao plano estratégico e operacional das empresas como fator de produtividade e competitividade. São Paulo: Makron Books, 1992. 
RUSSO, J. E.;

MEDVEC, V.H.;

MELOY,M.

The distortion of information during decisions. Organizational Behavior and human decision processos, New York, v. 66, n. 1, p. 102-110, apr. 1996.
STAL, E.

Centros de Pesquisa Cooperativa: um modelo eficaz de interação Universidade-Empresa? 1997. $220 \mathrm{f}$. Tese Doutorado em Administração FEA/USP, São Paulo. 